REVIEW

\section{Annual BDA Hospitals Group West Midlands Study Day}

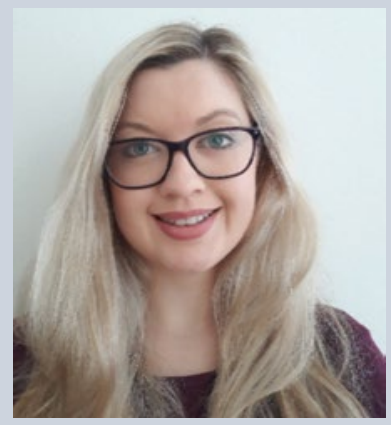
Hospital.
The annual BDA Hospitals Group West Midlands Division Study Day was held on 12 April 2019 at the Birmingham Dental

A cohort of 12 trainees had been selected to present at the study day, following an abstract submission. The presentations included an assortment of topics, including service

evaluations, audits and case reports, based on differing specialities, ranging from paediatrics and orthodontics to maxillofacial surgery.

The study day was enthusiastically opened by Mr John Turner (committee president and consultant orthodontist), who introduced each presenter, the guest speaker and three judges.

We were privileged to listen to guest speaker Dr Rachel Walker (Specialty Dentist \& Clinical Lecturer in Oral Surgery, Specialty Doctor in Palliative Care) on 'The Medical Dental Interface et al.'. She gave us an introduction into her background, her clinical commitments and delivered in depth knowledge on managing patients including and not limited to those who are anti-coagulated or take bisphosphonates.

Twelve presentations were delivered to compete for the Ivor Whitehead Prize. Each presentation was for ten minutes, followed by five minutes of questions, from both the audience and judges.

Mr Goldie Songra (Consultant Orthodontist), Dr Rachel Walker and Dr Kate Cullotty (Lead in Unscheduled Care) were the three judges selected for the challenging aspect of the event choosing the winners, based mainly on content and presentation quality.

The judging was made extremely challenging due to the calibre of the presentations. Nevertheless, I would like to congratulate Dr Razia Butt on first place in winning the Ivor Whitehead Prize. She presented 'The restorative management of a talon cusp: a case report'.

The study day was a fantastic and invaluable event, and a great learning experience for all. The content encompassed GDC development outcomes ABCDE. The day ended with thanks from Mr John Turner.

To conclude, I would like to take this opportunity on behalf of myself, Mr John Turner and Dr Sarah Martin (committee Treasurer) to encourage all trainees (including DFTs, DCTs and SpRs) to either attend or submit an abstract for the next annual study day (spring 2020 - date to be confirmed); it's an invaluable opportunity to advance your CPD hours, and also boost your CV.

Laura Rollings, Secretary of the BDA Hospitals Group West Midlands Division, Birmingham, UK

\section{Future CPD consultation open}

The General Dental Council (GDC) has published Shaping the direction of lifelong learning for dental professionals, which invites ideas, comments and views on the short and long-term future of professional learning and development in dentistry.

The publication represents the next step on the journey towards achieving a more effective system of CPD.

After building a robust base of evidence, the GDC says it 'now wishes to explore ideas for developing the CPD scheme with dental professionals and stakeholders' and that it is 'opening a conversation about what meaningful CPD is, how it can be achieved, and what the obstacles might be that prevent dental professionals from accessing and undertaking it'.

To take part in the consultation visit https://www.gdc-uk.org/about/ what-we-do/consultations.

\section{BOOK REVIEW}

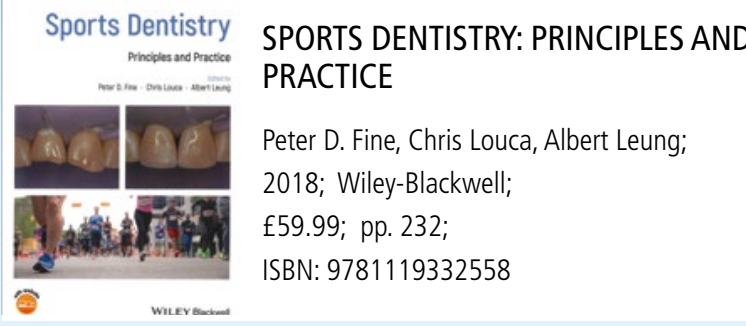

Sports dentistry is a modern speciality in postgraduate dentistry and this book provides a comprehensive guide for dental and medical practitioners. The key themes of the book include: orofacial trauma; dental screening in particular pre-season assessments; prevention of acute and chronic trauma; and the role of nutrients for athletes. The book explores the different elements of sports dentistry from dental trauma to adult and paediatric patients, including the subsequent challenges and considerations to restoring the tooth as well as endodontic problems.

Prevention within sports dentistry is essential, as athletes need to be assessed for tooth wear, prevention of sporting injuries and nutritional health. Oral health is a major factor in the performance of elite athletes. Excellent insight is provided with regards to dental screening, assembling equipment and setting up facilities at sporting events; there are multiple images and examples of how to achieve this.

The layout of the book is clear and concise for the reader, with a large range of contributors from different dental specialities and from the wider medical team to form a complete guide for dental and medical practitioners. The book is evidence-based and explores the underlying science and biology, enabling the reader to gain full comprehension of the different topics in relation to sports dentistry.

For those interested in what sports dentistry entails or pursuing further postgraduate training in the field, this book provides a thorough guide to different elements of the subject matter. The contents of this book form the basis for the sports dentistry programme at UCL Eastman Dental Institute.

Teresa $\mathrm{Ng}$ 